Gefässchirurgie 2020 · 25 (Suppl 1):S29-S36 https://doi.org/10.1007/s00772-020-00726-0 Accepted: 5 October 2020

Published online: 27 November 2020

(c) The Author(s) 2020

\author{
C.-A. Behrendt ${ }^{1} \cdot$ U. Rother ${ }^{2}$. G. Rümenapf ${ }^{3}$ C. Uhl $\cdot$ H. Görtz ${ }^{5}$ D. Böckler ${ }^{4}$. \\ Kommission PAVK und Diabetischer Fuß der DGG e.V. \\ 'Forschungsgruppe GermanVasc, Klinik und Poliklinik für Gefäßmedizin, Universitäres Herz- und \\ Gefäßzentrum UKE Hamburg, Universitätsklinikum Hamburg-Eppendorf, Hamburg, Germany \\ ${ }^{2}$ Gefäßchirurgische Abteilung, Universitätsklinikum Erlangen, Erlangen, Germany \\ ${ }^{3}$ Oberrheinisches Gefäßzentrum Speyer, Diakonissen-Stiftungs-Krankenhaus Speyer, Speyer, Germany \\ ${ }^{4}$ Klinik für Gefäßchirurgie und Endovaskuläre Chirurgie, Universitätsklinikum Heidelberg, Heidelberg, \\ Germany \\ ${ }^{5}$ Klinik für Gefäßchirurgie, Bonifatius Hospital Lingen, Lingen, Germany
}

\title{
Randomized controlled trials and real-world evidence for market access and surveillance of high- risk products-The example of paclitaxel
}

Manufacturers indicate with this marking that their products comply with the requirements applicable in the European Economic Area (EEA) trade area. In recent decades, critics of the $\mathrm{CE}$ marking have found fault with the excessively liberal market access and lack of surveillance over the entire life cycle of medical devices, especially high-risk medical devices (class III, e.g. implants). Catheters, stents and other cardiovascular implants are included in this category, which means that countless overlaps exist between the highest risk class and the fields of surgical interventional vascular medicine, radiology and angiology.

An interesting example illustrating the importance of market access and the surveillance of high-risk medical devices is the use of paclitaxel-coated stents and balloons to treat atherosclerotic peripheral vascular diseases. A controversial international debate on the safety of medical devices has raged since the end of 2018 when a meta-analysis of cumulative findings in randomized controlled trials (RCT) reported an association between the use of paclitaxel-coated products in the femoropopliteal artery and increased all-cause mortality after 2 years [18, 25]. Findings published in journals and presentations had to be corrected following the publication and the recruitment for ongoing studies was temporarily suspended. Several authorities including the German Federal Institute for Drugs and Medical Devices (Bundesinstitut für Arzneimittel und Medizinprodukte, BfArM) and the US Food and Drug Administration (FDA) issued corresponding warnings for the use of affected medical devices $[2,44]$. The findings of the first meta-analysis by Katsanos et al. were gradually confirmed in investigations by the FDA as well as in further meta-analyses that used patientlevel data along with additional data [32]. Meanwhile, an inverse association was observed in a number of real-world studies that used nonrandomized registry data and routinely collected data [5, $7,20,37]$. The two sides have responded with countless arguments in articles and at congresses without a conclusive outcome being reached [4]. A second meta-analysis by the same authors on the use of paclitaxel-coated balloons in infrapopliteal arteries rekindled this debate [19]. The findings confirmed the initial indications of higher complication and amputation rates previously suggested
The German version of this article can be found under https://doi.org/10.1007/10.1007/ s00772-020-00713-5 


\section{Reference Participating societies Recommendations}

and level of evidence

Frank European Society for Vas- Treatment of (longer and more complex) femoropopliteal lesions with drug-eluting balloons after predilata-

et al. [14] cular Medicine (ESVM) tion is recommended as standard of care (II, B)

Adequate vessel preparation is recommended for successful drug-eluting balloon or self-expanding stent application (I, B)

Mills et al. European Society for Vas- Insufficient evidence!

[25] cular Surgery (ESVS), So-

ciety for Vascular Surgery

(SVS), World Federation

of Vascular Societies

(WFVS)

Feldman Society for Cardiovas-

et al. [13] cular Angiography and Interventions (SCAI)

Aboyans European Society for

et al. [1] Cardiology (ESC), European Society for Vascular Surgery (ESVS)

Gerhard- American College of CarHerman diology (ACC), American et al. [15] Heart Association (AHA)

Lawall Association of the Sciet al. [3] entific Medical Societies in Germany (Arbeitsgemeinschaft der Wissenschaftlichen Medizinischen Fachgesellschaften e. V., AWMF), German Society for Angiology/Vascular Medicine (Deutsche Gesellschaft für Angiologie e. V., DGA)
Recommendations for drug-coated balloons as the intended definitive therapy in the femoropopliteal arterial interventions for CFA bifurcation lesion (IIA, C-EO), Above knee popliteal lesion (I, A), ostial SFA lesion (I, A), focal SFA lesion (I, A), intermediate SFA lesion (I, A), diffuse SFA lesion (I, B-R), moderate to severe calcified focal lesion (I, C-LD), moderate to severe calcified intermediate lesion (I, C-LD), moderate to severe diffuse lesion (I, C-LD), chronic total occlusion focal lesion (I, B-R), chronic total occlusion intermediate lesion (I, B-R), chronic total occlusion diffuse lesion (I, B-NR), ISR focal lesion (I, B-R), ISR intermediate lesion (I, B-R), ISR diffuse lesion (I, B-R)

Recommendations for drug-eluting stents as the intended definitive therapy in the femoropopliteal arterial interventions for CFA bifurcation lesion (IIA, C-EO), above knee popliteal lesion (I, B-R), ostial SFA lesion (I, $B-R)$, focal SFA lesion (I, B-R), intermediate SFA lesion (I, B-R), diffuse SFA lesion (I, B-NR), moderate to severe calcified focal lesion (I, C-LD), moderate to severe calcified intermediate lesion (I, C-LD), moderate to severe diffuse lesion (I, C-EO), chronic total occlusion focal lesion (I, B-R), chronic total occlusion intermediate lesion (I, B-R), chronic total occlusion diffuse lesion (I, B-NR), ISR focal lesion (IIB, C-LD), ISR intermediate lesion (IIA, C-LD), ISR diffuse lesion (IIA, C-LD)

Drug-eluting balloons may be considered in short (i.e. $<25 \mathrm{~cm}$ ) lesions (class llb, level A)

Drug-eluting stents may be considered for short (i.e. $<25 \mathrm{~cm}$ ) lesions (class Illb, level B)

Drug-eluting balloons may be considered for the treatment of in-stent restenosis (class llb, level B)

Insufficient evidence!

The clinical significance of drug-eluting stents cannot be sufficiently assessed at present (consensus recommendation).

If a reduced risk of restenosis and reintervention following angioplasty is considered essential in a clinical angiology context during the endovascular treatment of femoropopliteal lesions, paclitaxel-coated balloons should be used for angioplasty (II, B).

The significance of drug-coated balloons in angioplasty for infrapopliteal arteries cannot be sufficiently assessed (consensus recommendation)

CFA common femoral artery, SFA superficial femoral artery, $R$ randomized, NR nonrandomized, LD limited data, EO expert opinion, ISR in-stent restenosis

in the IN.PACT DEEP randomized trial [42].

This review examines the market introduction and rapid spread of paclitaxelcoated stents and balloons in vascular medicine. It draws on the divergent findings from randomized and nonrandomized studies to debate the strengths and limitations of complementary study designs for market access and surveillance.

\section{Randomized and nonrandom- ized studies on paclitaxel- coated stents and balloons}

Around 130 interventional paclitaxel studies were conducted between 2001 and 2020. These included 45 on specific stents or balloons, a total of 58,617 patients and substantial input from 6 manufacturers. Of the studies 21 are still underway.

The following clinical trials were the key to the development of the current market situation and the two meta-analyses by Katsanos et al.: THUNDER [39], ZILVER PTX $^{\mathrm{ms}}[2,11]$ and IN.PACT SFA [36] for treatment on the femoropopliteal artery, and LUTONIX BTK, [28] BIOLUX PII, [43] DEBATE-BTK, [24] ACOART II/ BTK, IN.PACT DEEP [42] and SINGAPACLI for vascular lesions below the knee. 


\section{Market dissemination and evolution of the guideline recommendations}

Following the discovery and isolation of the paclitaxel (Taxol) active ingredient from the bark of the Pacific yew tree in the 1960s and the preliminary description of its anticarcinogenic effects in the late 1970s, market access was granted for its use in coronary arteries in the early 2000s [25, 41]. The rationale for this was the inhibition of cytoskeleton metabolism by paclitaxel, which was already used in the treatment of countless types of malignant tumors. Due to the superiority of sirolimus-based medical devices, paclitaxel failed to prevail in the cardiological sector, with just a handful of exceptions [16, 23, 31, 34, 40]. While paclitaxel belongs to the group of cytostatic drugs, sirolimus (rapamycin) is an immunosuppressant (mammalian target of rapamycin, mTOR inhibitor) [27]. Various working groups and manufacturers have since investigated the effect in peripheral arteries of the lower extremities and developed corresponding products to market maturity. Since 2009, around 15 paclitaxel-coated balloons and 2 stents have been granted market access in Europe for the treatment of peripheral arteries. Almost 3 years later, 3 balloons and 1 stent were also approved in the USA for use in peripheral arteries [44]. Following their market introduction and dissemination in Europe and the USA, countless successive guidelines have included recommendations or considerations (• Table 1 ).

The preliminary indications of improved patency and reintervention rates following the use of paclitaxel-coated stents and balloons are discussed in the German S3 guidelines on the diagnosis, treatment and aftercare of peripheral arterial occlusive disease (PAOD) published by the German Association of the Scientific Medical Societies in Germany (Arbeitsgemeinschaft der Wissenschaftlichen Medizinischen Fachgesellschaften e. V., AWMF) in 2015 [3]. The authors emphasise that the evidence is insufficient, especially with respect to patient-relevant outcomes (e.g. walking distance, morbidity, mortality, quality of

Gefässchirurgie 2020 · 25 (Suppl 1):S29-S36 https://doi.org/10.1007/s00772-020-00726-0 (C) The Author(s) 2020

C.-A. Behrendt · U. Rother · G. Rümenapf · C. Uhl · H. Görtz · D. Böckler · Kommission PAVK und Diabetischer Fuß der DGG e.V.

\section{Randomized controlled trials and real-world evidence for market access and surveillance of high-risk products-The example of paclitaxel}

\section{Abstract}

In 2018 and 2020, two meta-analyses using summary-level data from randomized controlled trials reported worse mortality following the application of paclitaxel-coated stents and balloons in femoropopliteal and crural arteries. These results initiated a heated global discussion concerning the validity of this association, while various observational studies using clinical and administrative registries proved the safety of coated devices. This article aimed to summarize the development and adoption of paclitaxel- coated balloons and stents for the treatment of peripheral arterial occlusive disease in clinical practice, research, and practice guidelines. It especially focusses on the European Union's medical device regulation, which has far-reaching implications for the market approval and monitoring of high-risk medical devices.

Keywords

Routine data $\cdot$ Health-care research - Validity . Quality indicators · Administrative data

\section{Randomisierte kontrollierte Studien und Real-World-Evidence in der Marktzulassung und Überwachung von Hochrisikoprodukten - Das Beispiel Paclitaxel}

\section{Zusammenfassung}

In den Jahren 2018 und 2020 haben zwei Metaanalysen zu kumulativen Ergebnissen von randomisierten und kontrollierten Studien eine erhöhte Sterblichkeit nach der Anwendung Paclitaxel-beschichteter Stents bzw. Ballons in den Gefäßen der unteren Extremitäten berichtet. Im Anschluss daran entwickelte sich eine angeregte globale Diskussion über die Validität dieser Assoziation, wobei die Ergebnisse zahlreicher Beobachtungsstudien mit klinischen und administrativen Registerdaten die Anwendungssicherheit beschichteter Medizinprodukte nahelegten. Dieser Artikel fasst die Entwicklung und Verbreitung
Paclitaxel-beschichteter Ballons und Stents zur Behandlung der peripheren arteriellen Verschlusskrankheit in der klinischen Praxis, in Studien und in Leitlinien zusammen. Hierbei wird ein besonderer Fokus auf die neue Medizinprodukteregulation der Europäischen Union gelegt, die weitreichende Implikationen für die Marktzulassung und Überwachung von Hochrisikomedizinprodukten hat.

\section{Schlüsselwörter}

Routinedaten · Versorgungsforschung · Validität · Qualitätsindikatoren · Administrative Daten life, leg preservation). Therefore, it was not possible to assess the clinical value of coated stents sufficiently. Hence only a weak recommendation was issued for coated balloons in the femoropopliteal artery if the rate of restenosis or reintervention rate is considered significant (consensus recommendation). There was not enough evidence to recommend usage in infrapopliteal arteries [3].

The American College of Cardiology/ American Heart Association (ACC/AHA) published guidelines in 2016 [15]. Although the authors discuss a potential benefit of coated medical devices in pa- tients with intermittent claudication and critical limb ischemia, they do not expand on the effectiveness and efficiency of specific endovascular techniques. Rather, the guidelines also emphasize that no patient-oriented outcomes are available [15]. The guidelines of the European Society for Cardiology/European Society for Vascular Surgery (ESC/ESVS) published in 2017 review the available study data, which suggests better longterm patency when using coated devices in femoropopliteal arteries. In the corresponding (weak) recommendations, it is suggested that coated balloons or stents 
should therefore be considered for short $(<25 \mathrm{~cm})$ lesions of femoropopliteal arteries and coated balloons considered for in-stent restenosis (recommendation class IIB). To date, no study has found coated balloons to be superior to uncoated balloons in below the knee treatment [1].

In 2018, the Society for Cardiac Angiography and Interventions (SCAI) published consensus guidelines in which the importance of specific endovascular techniques, including paclitaxel-coated balloons and stents, is described. These guidelines contain a strong recommendation for use in femoropopliteal arteries based on high-quality evidence (recommendation class I) [13].

Two further guidelines containing recommendations or statements on the use of paclitaxel-coated balloons and stents in the lower extremities have been published since the first meta-analysis by Katsanos et al. [18]. In the global vascular guidelines (GVG) published in 2019 on the treatment of patients with critical limb ischemia, the three participating professional societies (European Society for Vascular Surgery, Society for Vascular Surgery, World Federation of Vascular Societies) included a statement on the safety of paclitaxel-coated medical devices in response to the international discussion. The authors emphasized the importance of further studies and stated that caution should be exercised when using coated balloons and stents outside of clinical trials [10].

Most recently, the 2019 guidelines published by the European Society for Vascular Medicine (ESVM) take up the ongoing discussion on the meta-analysis by Katsanos et al. [18]. Based on a secondary analysis of patient-level data from the LEVANT trial [29] and one of several available observational studies with routinely collected data, the authors concluded that the treatment of femoropopliteal lesions with coated balloons can be recommended as a standard of care (recommendation class II) [14].

\section{Meta-analyses of safety outcomes for paclitaxel-coated stents and balloons}

Countless RCTs and meta-analyses thereof can be drawn on in the international debate and as the basis for guideline recommendations on the use of coated medical devices in the lower extremities. While these primarily focus on technical outcomes (patency and reintervention rates), various systematic reviews and meta-analyses have been published since the end of 2018 on the long-term safety outcomes.

In 2018 Katsanos et al. included the published trial findings of 28 RCTs and 4663 patients with endovascular treatment of femoropopliteal arteries (approximately $90 \%$ with intermittent claudication) in the analyses for the first time. Allcause mortality was significantly higher in the paclitaxel group (vs. uncoated balloons or stents) at 2 years (12 RCTs with 2316 patients; $7.2 \%$ vs. $3.8 \%$, risk ratio: 1.68 ) and at 5 years (3 RCTs with 863 patients; $14.7 \%$ vs. $8.1 \%$, risk ratio: 1.93) [18]. In a further meta-analysis of individual patient data, Rocha-Singh et al. were able to examine the long-term data of a total of 2185 patients based on an intention-to-treat analysis and further sensitivity analyses. A total of 386 deaths (17.7\%) were registered within the 4-year follow-up period. The authors identified an absolute increase in all-cause mortality risk of $4.6 \%$ in the paclitaxel group; however, they could not find any evidence of a drug dose-mortality association [32]. Schneider et al. performed a patientlevel meta-analysis of 2 prospective clinical trials and 2 RCTs on coated balloons with a total of 1980 patients and a 5year follow-up period. In the analyses stratified by dose, no association could be discerned between paclitaxel and increased all-cause mortality [35].

Katsanos et al. also published a metaanalysis on the use of paclitaxel-coated balloons in arteries below the knee. Data from 8 RCTs encompassing 1420 patients (97\% with critical limb ischemia) was included in the analysis. After the 1-year follow-up period, higher rates of amputations and deaths were observed in the paclitaxel group ( $13.7 \%$ vs. $9.4 \%$; haz- ard ratio: 1.52 ), whereby this association was only significant in the group of balloons coated with a high dose [19]. Kuno et al. identified a total of 57 RCTs with 9362 patients. A comparison of seven different revascularization strategies returned no evidence of increased shortterm mortality after the use of coated balloons or stents or of increased longterm mortality after the use of coated stents; however, the use of paclitaxelcoated balloons was associated with increased long-term mortality [22]. Dinh et al. also investigated the association between mortality and paclitaxel-coated medical devices in patients with critical limb ischemia. A total of 11 RCTs with 1450 patients were identified, with a mean follow-up period of 25.6 months. The authors found no differences in the short-term and medium-term outcomes [12].

\section{Real-world evidence on paclitaxel-coated stents and balloons and the treatment reality in Germany}

In comprehensive longitudinal analyses of routinely collected data, a significant increase could be observed in the number of coated medical devices since their market access in Germany (2009). In the BARMER cohort, which included almost $10 \%$ of insured persons in Germany and enables a patient-level evaluation, just 111 patients had received a coated stent and 138 patients a corresponding balloon by 2009. In 2018, the proportion of coated devices thus increased from $3 \%$ for the treatment of critical limb ischemia and $4 \%$ for the treatment of intermittent claudication (2010) to $39 \%$ and $48 \%$, respectively $[5,17]$. A similar situation can be observed in practice patterns in the USA where around $50 \%$ of all procedures are today performed using coated stents or balloons [26]. In a Germanywide propensity score-matched and adjusted analysis of the primary outcomes of 1) overall survival, 2) amputationfree survival and 3) freedom from major cardiovascular events, no evidence was found of increased complications in the femoropopliteal or crural artery in the paclitaxel group $(37,914$ and 14,738 pa- 


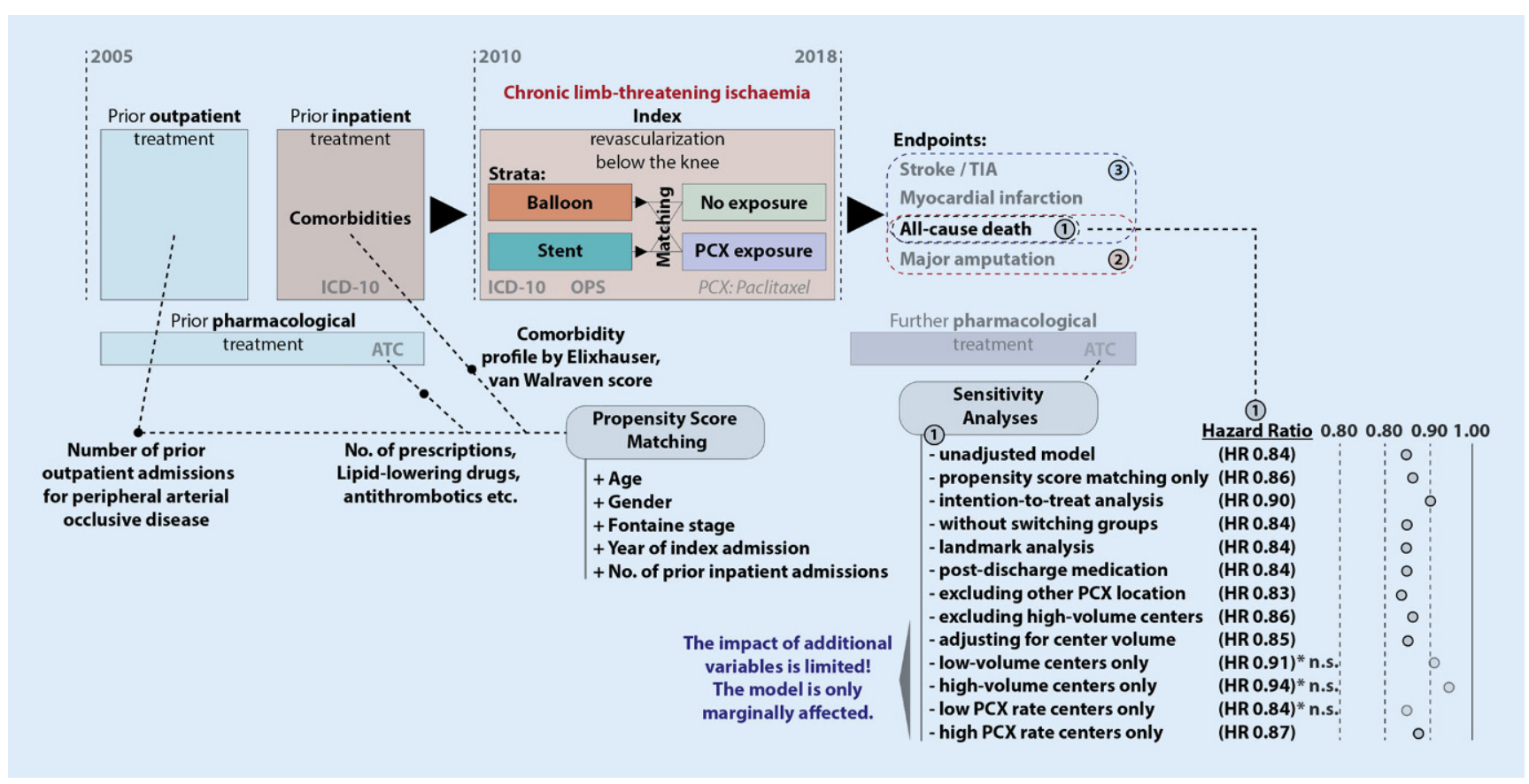

Fig. $1 \Delta$ Study design and influence of sensitivity analyses on the relationship between paclitaxel application and the primary endpoint total mortality in this propensity score matched retrospective evaluation of 14,738 patients. ICD international classification of diseases, OPS operational and procedure coding, ATC anatomical therapeutic chemical coding, TIAtransient ischemic attack, $P C X$ paclitaxel-coated devices

tients, respectively) after a 5-year followup period. Rather, an inverse association was discerned with improved outcomes following the index procedure, which could be confirmed in numerous sensitivity analyses [5, 17].

Comparable findings were discerned in international real-world data. In a weighted analysis of the administrative US Medicare database on 16,560 patients and 1883 hospitals, for which extended long-term data with US OPTUM routinely collected data has since also been presented at the Vascular Interventional Advances (VIVA) conference, the authors could not find any evidence of increased all-cause mortality in the follow-up period (median of 389 days or 2.65 years) [37]. In a further propensity score-matched registry data evaluation by the Society for Vascular Surgery (SVS) Vascular Quality Initiative (VQI) on 8376 patients with endovascular treatment of the femoropopliteal artery, it was discerned after the 1-year followup period that patients with critical limb ischemia had comparable mortality and patients with intermittent claudication had lower mortality [7]. A total of 2071 patients could be analysed in a mul- ticenter registry analysis at 3 hospitals in Great Britain and Greece. After a median follow-up period of 24 months, no higher mortality was observed in the group of patients treated with coated stents or balloons [33]. A retrospective singlecenter analysis is also available from Germany of balloon-supported angioplasties of the femoropopliteal artery from a high-volume centre. A total of 624 patients with critical limb ischemia were revascularized (68\% with a coated balloon). No disadvantages to survival were found in the paclitaxel group over the 3-year follow-up period [8].

\section{Debate}

In the midst of a comprehensive reform of the European Medical Device Regulation (MDR) and the related discussions on the long-term safety and surveillance of high-risk products, two independent meta-analyses ignited an intensive and controversial debate among the international vascular medicine community [18, 19]. The reported association between the use of paclitaxel-coated medical devices in femoropopliteal and crural arteries and increased all-cause mortality and amputation rates led to uncertainty among users and authorities alike. This was further exacerbated by the publication of errata and corrections.

The two sides countered in countless scientific journals and presentations with a multitude of arguments for or against an existing safety indication. Indeed, a consensus is still not foreseeable today [4]. The fact is that the association observed between paclitaxel and mortality could also be confirmed in further patient-level analyses, while various independent observational studies of a high methodological quality were able to prove an inverse association [5, 17, 32, 33, 37].

Both researchers working in the medical device industry and users have been left wondering how to assess the discordant studies. A central argument against the Katsanos et al. meta-analyses is the lack of evidence of a drug dose-mortality association [32]. Further arguments concern the selection of patients for study arms or subsequent changes to the study design. Exposure to paclitaxel through its use in other arteries or even in other therapeutic indications is also suggested as a possible cause of the excess mortality, underlining the extreme complexity of 
the target population. International networks for healthcare research and quality development such as the Medical Device Epidemiology Network (MDEpiNet) and its associated task forces are currently investigating the possible methodological aspects underlying the inverse associations in randomized versus non-randomized study designs. Essentially, it appears that the causal or predictive factors have not been adequately measured. The question therefore remains of the extent to which the cohorts of both study types differ. In the comprehensive sensitivity analyses of a large propensity scorematched routinely collected data analysis of the treatment of arterial lesions below the knee with paclitaxel-coated balloons or stents, it could be proven that the paclitaxel-mortality association is only marginally affected by the use of paclitaxel-coated products in other arteries, by the total case volume, by the postoperative drug supply or by the paclitaxel case volume (- Fig. 1 ; [17]). Against this background, the influence of an observational study's design is particularly interesting. Minor changes to the inclusion and exclusion criteria, stratification of different subgroups, adjustments and methods to take confounders into account, cause substantial shifts in the findings observed and conclusions reached. It could be shown in previous studies that a gradual approximation to the findings of RCTs can be achieved with growing complexity of the methodology and robustness of the model $[4,9]$.

The swift spread of new techniques and medical devices means that highrisk patients with complex comorbidities and lesions for whom treatment was not readily accessible in the past can today be treated. The rapid increase in the number of endovascular procedures (+61\% between 2010 and 2016) for the treatment of peripheral arterial occlusive disease (PAOD) and the overall rise in the number of treatment cases in Germany $(+23 \%)$ is impressive proof of this [21]. According to the latest VASCUNET report on the treatment of symptomatic PAOD in which almost 1.2 million treatments from 11 countries were included, Germany has slightly above-average proportions of elective treatments (60\%) and endovascular procedures $(66 \%)$ compared to its international counterparts [6]. That being said, in light of the inhomogeneous and changing guideline recommendations, this development also underlines the need for well-planned RCTs to provide the treating physicians with reliable bases for evidence and recommendation. The ongoing discussion and resulting uncertainty show that this has not been the case to date.

At the same time, although there is no way around sufficiently powered RCTs to prove causalities, observational studies without substantial selection bias remain the method of choice for quality assurance. While well-planned RCTs can adequately eliminate the influence of confounders on the procedure-outcome association, the generalizability and detection of rare occurrences is limited. The Idea Development, Exploration, Assessment, Long-term followup (IDEAL) statement for innovation in surgery highlights the complementary function of routinely collected data in the verification of the efficacy of procedures [38]. Against this background, the global paclitaxel debate provides a good illustration of the complementary benefits of different study designs. The extreme complexity of PAOD patient risk profiles and diverse treatments over their entire patient history mean the methodology must be carefully planned. It has been proven that around $25 \%$ of procedures performed on PAOD patients were reinterventions. This limits the use of caserelated or procedure-related datasets (e.g. data from the Institute for the Hospital Remuneration System (Institut für das Entgeldsystem im Krankenhaus, InEK) and intersectoral quality assurance pursuant to $\$ 137 \mathrm{a}$ of Book $\mathrm{V}$ of the German Social Code (SGB V)) or at least introduces substantial bias. As such, longitudinal research data from social insurance institutions can provide a valuable database to enable valid quality development over an appropriate follow-up period $[21,30]$.

It remains to be seen to what extent the European Medical Device Regulation (MDR) due to be introduced in May 2021 can improve the quality of the evidence base for the market access and surveillance of medical devices. The significance of high-quality real-world data from registers or routinely collected data has thus explicitly increased. Notified bodies have a particular responsibility in this respect during the review of scientific standards, transparency and data validity.

\section{Conclusions for professional practice}

- Around 15 balloons and 2 stents with a paclitaxel coating have been used in clinical practice since European market access (CE) was granted in 2009.

- Around half of all procedures to treat atherosclerotic lesions below the knee are now performed using coated balloons or stents.

- In a meta-analysis of the use of paclitaxel-coated balloons and stents in femoropopliteal arteries and a further meta-analysis on the use of coated balloons in arteries below the knee, increased all-cause mortality or less favorable amputation-free survival in the long-term could be proven following the use of these coated medical devices. These findings were confirmed in patientlevel analyses and independent analyses by the US Food and Drug Administration (FDA).

- In matched or weighted analyses of population-based routinely collected data and register data from the USA, Germany, Great Britain and Greece, no indications of a safety issue with coated medical devices could be discerned. Most of the trials were even able to prove lower mortality following the use of paclitaxel-coated products.

- The German Federal Institute for Drugs and Medical Devices (Bundesinstitut für Arzneimittel und Medizinprodukte, BfArM) calls on users of paclitaxel-coated medical devices to provide affected patients with appropriate information until the long-term safety has been confirmed.

- Numerous confounders, bias and diverse conflicts of interest affect insufficiently powered randomized 
and non-randomized trials alike and limit their generalizability and conclusiveness.

- Currently, the secondary use of longitudinal routinely collected data from social insurance institutions offers the only possibility to evaluate comprehensive long-term data, while case-related or procedure-related datasets are subject to significant bias due to the frequent reinterventions performed on the target population.

\section{Corresponding address

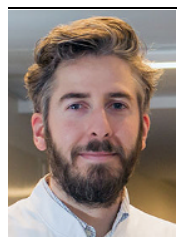 \\ PD Dr. C.-A. Behrendt \\ Forschungsgruppe \\ GermanVasc, Klinik und \\ Poliklinik für Gefäßmedizin, \\ Universitäres Herz- und \\ Gefäßzentrum UKE Hamburg, \\ Universitätsklinikum \\ Hamburg-Eppendorf \\ Martinistr. 52, 20246 Ham- \\ burg, Germany \\ behrendt@hamburg.de}

Funding. This work is financed using funds from the RABATT study (Innovation Fund of the German Federal Joint Committee (Gemeinsamer Bundesausschuss, G-BA); funding code: 01VSF18035; PI: (AB).

Funding. Open Access funding enabled and organized by Projekt DEAL.

\section{Compliance with ethical guidelines}

Conflict of interest. C.-A. Behrendt is chair of the Medical Device Epidemiology Network (MDEpiNet) Verband Deutschland e. V. and a member of the scientific advisory board of an accredited notified body (MEDCERT). U. Rother, G. Rümenapf, C. Uhl, H. Görtz and D. Böckler declare that they have no competing interests.

For this article no studies with human participants or animals were performed by any of the authors. All studies performed were in accordance with the ethical standards indicated in each case.

The supplement containing this article is not sponsored by industry.

Open Access. This article is licensed under a Creative Commons Attribution 4.0 International License, which permits use, sharing, adaptation, distribution and reproduction in any medium or format, as long as you give appropriate credit to the original author(s) and the source, provide a link to the Creative Commons licence, and indicate if changes were made. The images or other third party material in this article are included in the article's Creative Commons licence, unless indicated otherwise in a credit line to the material. If material is not included in the article's Creative Commons licence and your intended use is not permitted by statutory regulation or exceeds the permitted use, you will need to obtain permission directly from the copyright holder. To view a copy of this licence, visit http://creativecommons.org/licenses/by/4.0/.

\section{References}

1. Aboyans V, Ricco JB, Bartelink MEL et al (2018) Editor's choice - 2017 ESC guidelines on the diagnosis and treatment of peripheral arterial diseases, in collaboration with the European Society for Vascular Surgery (ESVS). Eur J Vasc Endovasc Surg 55:305-368

2. Anonymous (2019) Correction to: Durable clinical effectiveness with paclitaxel-eluting stents in the femoropopliteal artery 5-year results of the Zilver PTX randomized trial. Circulation 139:e42

3. Lawall et al (2016) S3-Leitlinie PAVK - Diagnostik, Therapieund Nachsorge der peripheren arteriellen Verschlusskrankheit. Vasa 45(Suppl 95):1-100

4. Behrendt CA, Peters F, Mani K (2020) The swinging pendulum of evidence: Is there a reality behind results from randomised trials and real world data? Lessons learned from the paclitaxel debate. Eur J Vasc Endovasc Surg 59:510-511

5. Behrendt CA, Sedrakyan A, Peters $F$ et al (2020) Editor's choice-Long term survival after femoropopliteal artery revascularisation with paclitaxel coated devices: a propensity score matched cohort analysis. Eur J Vasc Endovasc Surg 59:587-596

6. Behrendt CA, Sigvant B, Kuchenbecker Jet al (2020) International variations and gender disparities in the treatment of peripheral arterial occlusive disease-a report from VASCUNET and the International Consortium of Vascular Registries. Eur J Vasc Endovasc Surg. https://doi.org/10.1016/ j.ejvs.2020.08.027

7. BertgesDJ,Sedrakyan A, SunTetal (2020) Mortality after paclitaxel coated balloon angioplasty and stenting of superficial femoral and popliteal artery in the vascular quality initiative. Circ Cardiovasc Interv 13:e8528

8. Böhme T, Noory E, Beschorner U et al (In Press) Evaluation of mortality following paclitaxel drugcoated balloon angioplasty of femoropopliteal lesions in patients with ulcerations and gangrene-a single center experience. Vasa

9. Columbo JA, Martinez-Camblor P, Mackenzie TA et al (2018) Comparing long-term mortality after carotid endarterectomy vs carotid stenting using a novel instrumental variable method for risk adjustment in observational time-to-event data. JAMA Netw Open 1:e181676

10. Conte MS, Bradbury AW, Kolh P et al (2019) Global vascular guidelines on the management of chronic limb-threatening ischemia. Eur J Vasc Endovasc Surg 58:S1-S109.e133

11. Dake MD, Ansel GM, Jaff MR et al (2016) Durable clinical effectiveness with paclitaxel-eluting stents in the femoropopliteal artery: 5-year results of the Zilver PTX randomized trial. Circulation 133:1472-1483 (discussion 1483)

12. Dinh K, Gomes ML, Thomas SD et al (2020) Mortality after paclitaxel-coated device use in patients with chronic limb-threatening ischemia: a systematic review and meta-analysis of randomized controlled trials. JEndovasc Ther 27:175-185

13. Feldman DN, Armstrong EJ, Aronow HDet al (2018) SCAI consensus guidelines for device selection in femoral-popliteal arterial interventions. Catheter Cardiovasc Interv 92:124-140
14. FrankU, Nikol S, Belch Jet al (2019) ESVMguideline on peripheral arterial disease. Vasa 48:1-79

15. Gerhard-Herman MD, Gornik HL, Barrett $C$ et al (2017) 2016 AHA/ACC guideline on the management of patients with lower extremity peripheral artery disease: a report of the American College of Cardiology/American Heart Association task force on clinical practice guidelines. J Am Coll Cardiol 69:e71-e126

16. Grube E, Schofer J, Hauptmann KE et al (2010) A novel paclitaxel-eluting stent with an ultrathin abluminal biodegradable polymer. JACC Cardiovasc Interv 3:431-438

17. Heidemann F, Peters F, Kuchenbecker J et al (2020) Long term outcomes after revascularisations below the knee with paclitaxel coated devices: a propensity score matched cohort analysis. Eur J Vasc Endovasc Surg. https://doi.org/10.1016/j. ejvs.2020.06.033

18. Katsanos K, Spiliopoulos S, Kitrou Pet al (2018) Risk of death following application of paclitaxel-coated balloons and stents in the femoropopliteal artery of the leg: a systematic review and meta-analysis of randomized controlled trials. J Am Heart Assoc 7:e11245

19. Katsanos K, Spiliopoulos S, Kitrou Pet al (2020) Risk of death and amputation with use of paclitaxelcoated balloons in the infrapopliteal arteries for treatment of critical limb ischemia: a systematic review and meta-analysis of randomized controlled trials. J Vasc Interv Radiol 31:202-212

20. Krawisz A, Secemsky EA (2019) Real-world data collection regarding paclitaxel treatment. Endovasc Today 18:72-76

21. Kreutzburg T, Peters F, Riess HC et al (2020) Editor's choice-Comorbidity patterns among patients with peripheral arterial occlusive disease in Germany: a trend analysis of health insurance claims data. Eur JVasc Endovasc Surg 59:59-66

22. Kuno T, Ueyama H, Mikami T et al (2020) Mortality in patients undergoing revascularization with paclitaxel eluting devices for infrainguinal peripheral artery disease: insights from a network meta-analysis of randomized trials. Catheter Cardiovasc Interv. https://doi.org/10.1002/ccd. 29125

23. Lansky AJ, Costa RA, Mintz GS et al (2004) Nonpolymer-based paclitaxel-coated coronary stents for the treatment of patients with de novo coronary lesions. Circulation 109:1948-1954

24. Liistro F, Porto I, Angioli P et al (2013) Drugeluting balloon in peripheral intervention for below the knee angioplasty evaluation (DEBATEBTK): a randomized trial in diabetic patients with critical limb ischemia. Circulation 128:615-621

25. Mills JL, Conte MS, Murad MH (2019) Critical review and evidence implications of paclitaxel drugeluting balloons and stents in peripheral artery disease. JVasc Surg 70:3-7

26. Mohapatra A, Bertges DJ, Madigan MC et al (2018) Nationwide trends in drug-coated balloon and drug-eluting stent utilization in the femoropopliteal arteries. JVasc Surg 68:e15-e16

27. Moliterno DJ (2005) Healing Achilles-sirolimus versus paclitaxel. N Engl J Med 353:724-727

28. Mustapha JA, Brodmann M, Geraghty PJ et al (2019) Drug-coated vs uncoated percutaneous transluminal angioplasty in infrapopliteal arteries: six-month results of the Lutonix BTK trial. JInvasive Cardiol 31:205-211

29. Ouriel K, Adelman MA, Rosenfield K et al (2019) Safety of paclitaxel-coated balloon angioplasty for femoropopliteal peripheral artery disease. JACC Cardiovasc Interv 12:2515-2524 


\section{PAVK}

30. Peters F, Kreutzburg T, Kuchenbecker J et al (2020) Behandlungsqualität in der operativinterventionellen Gefäßmedizin - was können Routinedaten der Krankenkassen leisten? Gefässchirurgie. https://doi.org/10.1007/s00772-02000664- $x$

31. Rissanen TT, Uskela S, Eränen J et al (2019) Drugcoated balloon for treatment of de-novo coronary artery lesions in patients with high bleeding risk (DEBUT): a single-blind, randomised, noninferiority trial. Lancet 394:230-239

32. Rocha-Singh KJ, Duval S, Jaff MR et al (2020) Mortality and paclitaxel-coated devices. Circulation 141:1859-1869

33. Saratzis A, Lea T, Yap T et al (2020) Paclitaxel and mortality following peripheral angioplasty: an adjusted and case matched multicentre analysis. Eur J Vasc Endovasc Surg 60:220-229

34. Scheller B, Hehrlein C, Bocksch W et al (2006) Treatment of coronary in-stent restenosis with a paclitaxel-coated balloon catheter. N Engl J Med 355:2113-2124

35. Schneider PA, Laird JR, Doros G et al (2019) Mortality not correlated with paclitaxel exposure: an independent patient-level meta-analysis of a drug-coated balloon. J Am Coll Cardiol 73:2550-2563

36. Schneider PA, Laird JR, Tepe G et al (2018) Treatment effect of drug-coated balloons is durable to 3 years in the femoropopliteal arteries: long-term results of the IN.PACT SFA randomized trial. Circ Cardiovasc Interv 11:e5891

37. Secemsky EA, Kundi H, Weinberg I et al (2019) Association of survival with femoropopliteal artery revascularization with drug-coated devices. JAMA Cardiol 4:332-340

38. Sedrakyan A, Campbell B, Merino JG et al (2016) IDEAL-D: a rational framework for evaluating and regulating the use of medical devices. BMJ 353:i2372

39. Tepe G, Schnorr B, Albrecht T et al (2015) Angioplasty of femoral-popliteal arteries with drug-coated balloons: 5-year follow-up of the THUNDER trial. JACC Cardiovasc Interv 8:102-108

40. Zhang X, Xie J, Li G, Chen Q, Xu B (2014) Head-tohead comparison of sirolimus-eluting stents versus paclitaxel-eluting stents in patients undergoing percutaneous coronary intervention: a metaanalysis of 76 studies. PLoS One. https://doi.org/ 10.1371/journal.pone.0097934

41. Yang C-P, Horwitz S (2017) Taxol $^{\circledR}$ : the first microtubule stabilizing agent. Int J Mol Sci 18(8):1733

42. Zeller T, Baumgartner I, Scheinert $D$ et al (2014) Drug-eluting balloon versus standard balloon angioplasty for infrapopliteal arterial revascularization in critical limb ischemia: 12month results from the IN.PACT DEEP randomized trial. J Am Coll Cardiol 64:1568-1576

43. Zeller T, Beschorner U, Pilger E et al (2015) Paclitaxel-coated balloon in infrapopliteal arteries: 12-month results from the BIOLUXP-II randomized trial (BIOTRONIK'S-first in man study of the Passeo-18 LUX drug releasing PTA balloon catheter vs. the uncoated Passeo-18 PTA balloon catheter in subjects requiring revascularization of infrapopliteal arteries). JACC Cardiovasc Interv 8:1614-1622

44. Zeller T, Noory E, Beschorner U et al (2019) Outstanding effectiveness of paclitaxel-based technologies for the treatment of femoropopliteal artery occlusive disease on the potential expense of increased late all-cause mortality? No reason to panic. Vasa 48:109-111 